https://helda.helsinki.fi

\title{
Values that Underlie and Undermine Well-Being : Variability Across Countries
}

\section{Sortheix, Florencia M.}

2017-03

Sortheix , F M \& Schwartz , S H 2017 , ' Values that Underlie and Undermine Well-Being :

Variability Across Countries ' , European Journal of Personality , vol. 31 , no. 2 , pp. 187-201

. https://doi.org/10.1002/per.2096

http://hdl.handle.net/10138/225090

https://doi.org/10.1002/per.2096

acceptedVersion

Downloaded from Helda, University of Helsinki institutional repository.

This is an electronic reprint of the original article.

This reprint may differ from the original in pagination and typographic detail.

Please cite the original version. 


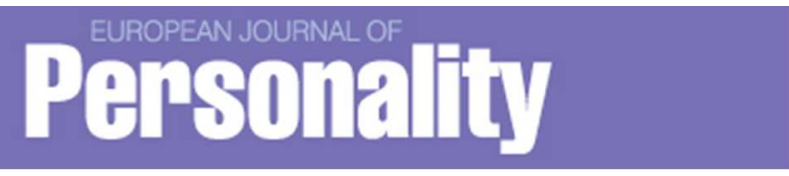

\section{Which values underlie or undermine happiness? Country- level moderation}

\begin{tabular}{|r|l|}
\hline Journal: & European Journal of Personality \\
\hline Manuscript ID & Draft \\
\hline Wiley - Manuscript type: & Research Article \\
\hline Date Submitted by the Author: & n/a \\
\hline Complete List of Authors: & $\begin{array}{l}\text { Sortheix, Florencia; Helsingin yliopisto Kayttaytymistieteellinen tiedekunta, } \\
\text { Institute of Behavioral Sciences } \\
\text { Schwartz, Shalom; The Hebrew University of Jerusalem, Psychology }\end{array}$ \\
\hline Manuscript Keywords: & $\begin{array}{l}\text { values, subjective well-being, cultural egalitarianism, Cross-cultural } \\
\text { research, European Social Survey }\end{array}$ \\
\hline
\end{tabular}

\section{SCHOLARONE ${ }^{m}$}

Manuscripts 


\section{Which values underlie or undermine happiness? Country-level moderation ${ }^{1}$}

The last decades have witnessed increased interest in the scientific study of well-being. Of the various constructs used to study this concept, subjective well-being (SWB) is the most widely used measure of happiness across countries (for a review, see Diener, Oishi, \& Lucas, 2003). Today, several countries complement their economic indicators of well-being with measures of SWB (Diener, Lucas, Schimmack, \& Helliwell, 2009). SWB includes a cognitive component (i.e., life satisfaction) and an emotional component (positive and negative affect) (Bradburn, 1969; Lucas, Diener, \& Suh, 1996). SWB relates positively to numerous desirable health, work, and family outcomes (Howell, Kern, \& Lyubomirsky, 2007; Lyubomirsky, King, \& Diener, 2005). It is therefore important to understand the individual level variables that foster or undermine SWB, as well as the characteristics of the life context that may moderate effects of these predictors on SWB (cf. Kööts-Asumees \& Realo, 2015; Sortheix \& Lönnqvist, 2014).

The current study examines relations of SWB to personal values in large representative national samples. Personal values are broad goals, varying in importance, that underlie and guide attitudes and behavior (Rokeach, 1973, Schwartz, 1992). Past research has suggested that SWB relates systematically to the values people pursue. This research has largely adopted one of two perspectives (Sagiv, Roccas, \& Oppenheim, 2015). The 'healthy' values perspective proposes that pursuing values that satisfy psychological needs for growth and self-actualization directly promotes SWB, whereas pursuing values that promote self-aggrandizement and self-interest directly undermines SWB (e.g., Bobowik, Basabe, Páez, Jiménez, \& Bilbao, 2011; Sagiv \& Schwartz, 2000). The 'value congruence' perspective proposes that the fit between the values

\footnotetext{
${ }^{1}$ An earlier version of this paper was presented at the International Conference on the European Social Survey in November 2012.
} 
pursued and the opportunities and constraints in the context determines the values that promote or undermine SWB (e.g., Sagiv \& Schwartz, 2000; Sortheix \& Lönnqvist, 2014).

The two perspectives are not necessarily contradictory. In most contexts, specific values may promote SWB (e.g., benevolence) or undermine it (e.g., power). So these values appear to be healthy or unhealthy in general. In particular circumstances, however, these values may not relate to SWB at all and may even have a reverse effect (e.g., a positive effect of power values in a business school context; Sagiv \& Schwartz, 2000). Studies in various samples and countries show inconsistent value-SWB associations (e.g., Bilbao, Techio, \& Paez, 2007; Bobowik et al., 2011; Cohen \& Shamai, 2009; Joshanloo \& Ghaedi, 2009; Sortheix \& Lönnqvist, 2014). Thus far, there is no theoretical model that explains these inconsistencies.

In the current study, we propose a theoretical model to explain which values are likely to relate positively or negatively to SWB or to show no overall association. The model also specifies how cultural value contexts may moderate individual level value-SWB associations. We assess the model with data from 32 countries. We examine the ten basic values from Schwartz (1992) and apply his theorizing about the dynamic underpinnings of these values (Schwartz, 2006b, 2010). We analyze value-SWB associations in representative national samples across a larger and more diverse set of countries than previously studied. To represent SWB, we measure both its cognitive component (life satisfaction) and an affective component (depressive affect).

\section{The Schwartz Theory of Basic Individual Values}

Schwartz (1992) defines values as broad motivational goals that transcend specific situations, serve as guides to behavior and as criteria for judging people and events. Values are 
ordered hierarchically according to their importance. Each value is defined by the goals towards which it is directed, that is, the motivation it expresses. Table 1 presents the ten basic values and the goals that define them. According to Schwartz (1992), these values form a circular motivational continuum (Figure 1). Values close in the circle express compatible motivations; the same actions can easily express both motivations. Values distant in the circle express competing motivations; the same actions cannot easily express both motivations.

Four higher order values summarize the oppositions between competing values (second circle from the center of Figure 1). 'Openness to change' versus 'conservation' captures the conflict between values that emphasize independence of thought, action, and feelings and readiness for change and values that emphasize order, self-restriction, and resistance to change. 'Selfenhancement' versus 'self-transcendence' captures the conflict between values that emphasize concern for the welfare and interests of others and values that emphasize pursuit of one's own interests, relative success, and dominance. Hedonism shares elements of both openness to change and self-enhancement.

The interests that value attainment serves are a second motivational principle organizing the value circle (Schwartz, 1992, 2006b). The person-focused values on the left of Figure 1 primarily regulate how one expresses one's own personal characteristics and interests. The social-focus values on the right primarily regulate how one relates socially to others and preserves cooperative relations.

Finally, relations of values to anxiety also organize the circle (Schwartz 2006b, 2010). Values in the bottom part of the circle are based in the need to avoid or control anxiety and threat and thereby to protect the self. Conservation values avoid conflict, unpredictability, and change by submitting and passively accepting the status quo. Power values seek to overcome anxiety by 
actively controlling threat. In contrast, values in the top part of the circle express growth and self-expansion. They are relatively anxiety free. Self-transcendence values promote the welfare of others and nature. Openness to change values emphasize autonomous, self-expressive experience. The line separating self-protection from growth values falls in the middle of the achievement wedge in Figure 1. Achievement values have both protection and growth components; they control anxiety by meeting social standards, but they thereby affirm the personal sense of competence.

\section{Past theorizing and research}

Sagiv and Schwartz (2000) drew on Maslow’s hierarchy of needs (1954) and on Bilsky and Schwartz's (1994) concepts of growth and deficit values to identify 'healthy' vs. 'unhealthy' values. They suggested that pursuing growth values (self-direction, benevolence, universalism, achievement, and stimulation) should promote well-being because they are self-actualizing. In contrast, pursuing deficit values (conformity, tradition, security, and power) should undermine well-being because they reflect the need to protect oneself against insecurity and threat.

Others (reviewed in Sagiv, Roccas \& Oppenheim, 2015) have drawn on selfdetermination theory (e.g., Deci \& Ryan, 2000) to argue that values directed toward intrinsic goals of relatedness, autonomy, and competence should relate positively to SWB. Universalism, benevolence, self-direction, and achievement are such values. Conversely, values directed toward extrinsic goals of wealth, fame, and popularity/attractiveness should relate negatively to SWB (Deci \& Ryan, 2000; Kasser, Ryan, Couchman, \& Sheldon, 2004). Power and, perhaps, achievement and conformity are such values. 
Seven studies report correlations between values and subjective life satisfaction or positive affect (Bilbao, Techio, \& Paez, 2007; Bobowik, et al., 2011; Cohen \& Shamai, 2009; Joshanloo \& Gahedi, 2009; Oishi, Diener, Lucas, \& Suh, 1999; Sagiv \& Schwartz, 2000; Sortheix \& Lönnqvist, 2014). Online supplement A summarizes the findings of these studies. For life satisfaction, there were no fully consistent findings. Hedonism, stimulation, self-direction, and benevolence tended to relate positively, power to relate negatively, and tradition, conformity, security, achievement, and universalism showed no clear trend. Similar results were reported for positive affect. In sum, although there were trends, there was much inconsistency.

Sortheix and Lönnqvist (2014) sought to clarify some of this inconsistency. In a multilevel analysis, they treated the socio-economic development of countries as a moderator of relations between values and the life satisfaction (LS) component of SWB. They analyzed data from 25 national representative samples from the 2006-7 round of the European Social Survey (ESS) and used Human Development Index scores (HDI, 2006) to measure countries' level of development. They argued that the associations between values and life satisfaction depend on how well a value aligns with the socio-economic context in the country, the fit of the value to the environment. They posited that social-focused values (self-transcendence and conservation) would promote LS in high HDI countries because the context of economic welfare and democracy makes investing in cooperative social relations beneficial. In contrast, selfenhancement or egoistic values would undermine LS in this context. They further posited that person-focused values (self-enhancement and openness to change) would promote LS in low HDI countries because the context of underdevelopment and neediness makes investing in personal advancement and coping with change necessary to adapt successfully. In contrast, social focused values (conservation and universalism, but not benevolence) would undermine LS in this 
context. They expected benevolence to relate positively to LS across contexts because it contributes to better interpersonal relationships that are crucial for wellbeing.

The pattern of associations supported their idea that the associations vary as a function of national levels of socio-economic development, but did not support part of their theorizing: Simple-slopes results showed that in high HDI countries, the social-focused security, conformity, and universalism values were not significantly related to LS. Also contrary to expectations, under low HDI, the person-focused power value related negatively to LS. Moreover, their distinction between social- vs. person-focused values provided no rationale to explain why openness to change values related positively to LS in high HDI countries. Thus, there is a need to go beyond the distinction between social- vs. person-focused values to account for associations between values and SWB.

\section{The Current Study}

As noted, we investigate value-SWB associations with both life satisfaction (LS) and depressive affect (DEP). Although LS and DEP are not opposite poles of a continuum, they operate in parallel (e.g., Cacioppo \& Berntson, 1999). The LS measure used in this study refers to how satisfied and happy people are with their lives in general. The DEP measure is the frequency with which respondents experienced feelings symptomatic of depression during the past week. LS and DEP affect differ conceptually not only in valence (positive vs. negative), but also in their level of activation (medium vs. low) (Russell \& Carroll, 1999). Nonetheless, in this study, the two measures correlated moderately negatively $(r=-.46)$. We expected personal values to relate to them in opposite directions. Thus, we formulate our hypotheses based on research findings and expectation mainly concerning LS. DEP is a second outcome variable that 
can shed light on the robustness of the hypotheses to negative SWB. To simplify the formulation of hypotheses, we use "high SWB" to refer to high LS and to low DEP.

\section{A theoretical model for predicting direct value-SWB associations}

To predict direct associations between values and SWB, we consider the interplay of two sources of the dynamic organization of the value circle (Schwartz, 2006b, 2010). First is the opposition of self-protective, anxiety-based values vs. self-expansive, growth values, second, the opposition of social vs. personal focus. In addition, we propose a contextual variable, Cultural Egalitarianism, as a moderator of associations between personal values and SWB.

Table 2 presents an overview of our theoretical model for predicting direct associations of personal values with SWB. The signs in this 2 X 2 table indicate the predicted directions of association for the values in each quadrant. These predictions derive from the combination of the two sets of underlying motivations that the values express, noted above: growth vs. selfprotection orientation and person vs. social focus (cf. Figure 1). We expect the motivation for growth and self-expansion, with relative freedom from anxiety, to promote SWB. Such motivation promotes pursuit of the intrinsically satisfying needs of autonomy, relatedness, and competence (e.g., Deci \& Ryan, 2000; Sagiv et al., 2015; Sagiv \& Schwartz, 2000). In contrast, we expect the motivation to protect the self and avoid anxiety to accompany or even foster poor SWB. Such motivation reflects a perceived need to overcome or prevent threat and uncertainty when the environment is seen as unpredictable, unsafe, or threatening, physically or psychologically (Schwartz, 2015).

Regarding the distinction between person- vs. social-focus, we expect the person-focus motivation to be conducive to SWB. Such motivation encourages individuals to pursue their own 
goals, to behave autonomously while developing and expressing their personal capacities and interests. In contrast, the motivation underlying social-focused values is likely to undermine SWB. Such motivation elicits concern regarding the expectations, needs, and problems of others with whom one is in contact and of the larger society. Furthermore, whereas the pursuit of person-focus values depends mainly on individual efforts and actions, reaching the goals of social-focus values (e.g., equality, secure surroundings) depends heavily on actions by others and circumstances in the larger society.

The three openness to change values (hedonism, stimulation, and self-direction) combine a growth orientation with a person focus. We therefore hypothesize that they relate positively to SWB. A positive association with well-being is consistent with prior findings in three large samples (Bilbao, Techio, \& Paez, 2007; Bobowik et al., 2011; Sortheix \& Lönnqvist, 2014). Pursuing openness to change values satisfies intrinsic needs for autonomy (i.e., being the agent of one's actions), thereby promoting SWB. These values welcome novelty and challenge, fostering an active, out-going, expression of feelings and ideas that is compatible with high LS but discordant with depressive affective states. People who feel anxious, sad, pessimistic, and unable to get themselves going, aspects included in the depressive affect measured here, are unlikely to pursue openness to change values (Grucza, Przybeck, Spitznagel, \& Cloninger, 2003).

The three conservation values (security, conformity, and tradition) combine a selfprotection orientation with a social focus. We therefore hypothesize that all three conservation values relate negatively to SWB. This hypothesis is consistent with findings for security and conformity in two large sample studies (Bobowik et al., 2011; Sortheix \& Lönnqvist, 2014). 
The increased importance of all three of these values in response to the threatening, uncertainty, and anxiety-arousing circumstances of a terrorist attack (Verkasalo, Goodwin, \& 2006) and of migration to a new country (Lönnqvist, Jasinskaja-Lahti, \& Verkasalo, 2011) illustrates their self-protective orientation.

Hypotheses for self-transcendence and self-enhancement values are more complex because the motivations for growth vs. protection and social vs. personal interests that underlie them have opposing implications for SWB. First, consider universalism, a self-expansive growth value with a social focus. It expresses concern for the welfare of all others in the wider society and for nature and it motivates behavior to ameliorate the problems one perceives. However, such behavior rarely solves persistent societal or worldwide problems. So focusing on such problems is discouraging and may counteract the positive effects of the growth orientation. Without grounds to postulate which factor is stronger, we expect the tradeoff between growth and social focus to result in no overall association between universalism values and SWB.

Benevolence shares the same underlying motivations as universalism, but its social focus is on relations with close others. The behaviors that benevolence values foster are likely to promote positive relations with family and friends, thereby satisfying relatedness needs (Deci \& Ryan, 2000). Although concern for the needs and problems of close others can be distressing, it motivates helpful and cooperative behavior (Schwartz, 2010) that can enhance SWB. We therefore hypothesize that benevolence values relate positively to SWB, consistent with prior findings in large samples (Bobowik et al., 2011; Sortheix \& Lönnqvist, 2014).

Next, consider power values. The self-protective motivation underlying these values implies a perceived need to control or overcome threats to one's status that contributes negatively to SWB. On the other hand, power values express personal aspirations and interests 
and might therefore be expected to promote SWB. However, the goals whose pursuit they motivate, dominance and wealth, are extrinsic (Deci \& Ryan, 2000). Seeking them increases anxiety and depressive symptoms (Kasser et al., 2004). Moreover, pursuing dominance is liable to elicit negative reactions from others. Thus, overall, emphasizing power values should relate negatively to SWB, consistent with prior findings in the large samples (Bobowik et al., 2011; Sortheix \& Lönnqvist, 2014).

Achievement values express a motivation to demonstrate competence and attain approval from others for one's success. The self-protective concern with others' evaluations and the extrinsic nature of the goal of social approval/popularity undermine SWB. However, the personfocused goal of achievement values, developing one's actual competence, is a core intrinsic goal (Deci \& Ryan, 2000). This may promote SWB and offset the negative effect of the protection motivation. The combination of offsetting factors leads us to expect no overall association of achievement values with SWB (cf. Bobowik et al., 2010).

Hypothesis 1: Openness to change values (self-direction, stimulation and hedonism) relate positively to SWB.

Hypothesis 2: Conservation values (tradition, conformity and security) relate negatively to SWB. Hypothesis 3: Benevolence values relate positively to SWB.

Hypothesis 4: Power values relate negatively to SWB.

\section{Egalitarian cultural values as moderators of value-SWB relations}

Cultural values refer to the normative system of value emphases in a society. They reflect a society's adaptations to its unique ecological, historical, economic, political, and demographic experiences. These cultural values underlie the functioning of informal and formal societal 
institutions (Schwartz, 2006a, 2014). Cultural Egalitarianism is one alternative adaptation to the problem of how to induce people to behave cooperatively and thereby preserve the social fabric. In egalitarian cultures, people are socialized to engage voluntarily in collaborative, productive work, based on internalized commitments. They are expected to view all people as morally equal and to act for the benefit of the larger society out of personal choice rather than in response to external demands and control (Schwartz, 2006a).

Countries' levels of Cultural Egalitarianism correlate positively with their level of development, democracy, and rule of law and with the proportion of their wealth that they spend on health, social security, unemployment and sickness benefits (Schwartz, 2014; Siegel, Licht, \& Schwartz, 2011). More culturally egalitarian societies provide a supportive and predictable environmental context that encourages and supports cooperative efforts that multiply individuals' capacities. Such societies provide much that individuals need. In contrast, the context in low egalitarian societies supplies much less. The environment is more threatening, unstable, anxiety provoking and constraining. Normative support for cooperation is low and competitive striving more legitimate. Individuals must draw more upon their own capacities and resources and take personal initiatives in order to succeed.

We base our hypotheses for cross-level moderation by Egalitarianism on person-situation fit and congruence ideas widely used in organizational literature (Kristof, 1996; O'Reilly, Chatman, \& Caldwell, 1991). Complementary fit is the relevant mechanism that can generate compatibility between personal characteristics and the situation: At least one entity provides what the other needs (Cable \& Edwards, 2004). This refers to occasions when "the weaknesses or needs of the environment are offset by the strength of the individual, and vice-versa" (Muchinsky \& Monahan, 1987, p. 271). It occurs when individuals' characteristics can supply 
what is missing or needed in the context and/or when the context can provide what individuals demand or need.

The idea of complementary fit suggests that person-focused values confer a special advantage in low egalitarian societies. Pursuit of person-focused values implies active, individual efforts to attain personal interests and to develop and express one's own ideas and capacities even if doing so challenges the status quo and introduces change. These actions can compensate, at least partially, for what is lacking in the non-supportive and threatening circumstances of low egalitarian societies. In contrast, the more passive pursuit of harmony that social-focused values imply is less likely to compensate for what a low egalitarian society lacks. The motivation for these values is unlikely to generate the individual energy and skill needed to cope successfully with the recalcitrant institutions on which people depend or the self-assertiveness to defy or work around prevailing difficult circumstances. We draw upon these ideas in developing the interaction hypotheses for each value below.

Earlier, we hypothesized that openness to change values relate positively to SWB (H1). This is even more the case in low egalitarian societies. Those who endorse these values are better equipped to deal with the problems inherent in these societies. In addition to the advantages of person-focused values listed above, openness to change values foster tolerance for ambiguity (Bardi et al., 2009) and pursuit of new and creative ways to cope (Schwartz, 2015). Thus, openness to change values are particularly helpful in enabling individuals to compensate for the lack of stability and support that characterize low egalitarian societies.

Hypothesis 5: Openness to change values relate more positively to SWB in countries with less egalitarian cultures. 
Regarding self-enhancement values, we earlier hypothesized that power values relate negatively to SWB (H4). We proposed no directional hypothesis for achievement values because they include offsetting approval and competence motivations (cf, Bobowik et al., 2010). Power and achievement, as person-focused values, provide the advantages in low egalitarian contexts noted above. This should somewhat mitigate negative impacts on SWB. This is in line with the weaker negative association of power with SWB in less socio-economically developed countries that Sortheix and Lönnqvist (2013) reported. Power values may additionally compensate for what is lacking in low egalitarian societies because they motivate individuals to assert themselves and compete for scarce resources of wealth and power. Achievement values may also help individuals to succeed in this competitive and challenging environment because they motivate demonstrating competent performance.

Hypothesis 6: Power values (6a) and Achievement values (6b) relate less negatively to SWB in countries with less egalitarian cultures.

We hypothesized that conservation values relate negatively to SWB (H2). This is even more the case in low egalitarian societies. The disadvantages of social-focused values listed above leave those who endorse them more poorly equipped to cope with the challenges and engage in the striving needed to compensate for what is lacking in these societies. Moreover, conservation values reflect especially great vulnerability to the anxiety-provoking potential of the threat, instability, and uncertainty characteristic of low egalitarian societies. Hypothesis 7: Conservation values relate more negatively to SWB in countries with less egalitarian cultures.

Regarding self-transcendence values, we earlier hypothesized that benevolence values relate positively to SWB (H3). We proposed no directional hypothesis for universalism values. 
We suggested that the positive impact of commitment to the welfare of all others on SWB may be offset by the negative impact of frustration from the intractability of societal problems. As social-focused values, benevolence and universalism lead individuals to seek harmony through cooperation rather than to act in the assertive, self-interested, and competitive ways that are more likely to foster success in low egalitarian societies. Thus, self-transcendence values may handicap individuals as they try to acquire the resources that they, their families, or the social groups they seek to help need. Moreover, the needs of others that benevolence and universalism values aim to relieve are greater in low egalitarian societies. So the intensity of personal concern that these values elicit is liable to be greater, undermining SWB.

Hypothesis 8: Universalism values (8a) and benevolence values (8b) relate less positively to SWB in countries with less egalitarian cultures.

\section{Methods}

\section{Participants}

Participants were individuals from the first three rounds of the European Social Survey (ESS, NSD 2002-2007) who responded to the measures used here. The ESS conducted face-toface interviews with strict probability samples, representative of the population 15 years and older, in 32 countries. Data were downloaded from www.ess.nsd.uib.no. The sample for life satisfaction included 121,495 respondents from the 2002/3, 2004 and 2006 rounds of the ESS. The sample for depressive affect (measured only in the 2006 round) included 42,972 respondents from 25 countries. We weighted responses using design weights provided by the ESS to correct for different probabilities of selection. Online supplement B provides the individual and countrylevel demographic breakdown.

\section{Measures}


Life satisfaction (LS). Two items assessed general life satisfaction: "How satisfied are you with life as a whole?" and "how happy are you? Responses on $11 \mathrm{pt}$ anchored scales (0extremely dissatisfied/unhappy, 10-extremely satisfied/happy) were averaged to create a single score. Average Cronbach's alpha across countries was .78 (range .69 to .86). The ESS country rankings for happiness and life satisfaction are almost identical $(r=.987)$ (Helliwell, Layard, \& Sachs, 2012).

Depressive affect. Six items from the Center for Epidemiologic Studies-Depression (CESD; Radloff, 1977) scale measured depressive affect. They asked how often in the week before the survey respondents had felt each of the following: felt depressed, felt that everything was an effort, slept badly, felt lonely, felt sad, and could not get going. Labeled response categories ranged from 1-none or almost none of the time to 4-all or almost all of the time. Average Cronbach's alpha across countries was .81 (range .68 to .87). Van de Velde, Bracke, Levecque, and Meuleman (2010) established the partial metric invariance of the 8-item version of this scale $^{2}$ across gender and countries.

Personal values. We measured personal values with the 21 -item version of the Portrait Values Questionnaire (PVQ21) adapted by Schwartz (2005) for the ESS. Each item describes a different person in terms of what is important to him/her. Respondents are asked: "How much like you is this person?" on a scale from 1 -very much like me to 6 -not like me at all. We recoded responses so that higher scores represent greater similarity. Reliabilities of the two-item indexes of the values (three for universalism) averaged .55 , ranging from .38 for tradition to .69

\footnotetext{
${ }^{2}$ We excluded two items that asked how often people felt they enjoy life and felt happy in order to avoid overlap with our measure of LS.
} 
for achievement. As expected, they were low, because each value is intended to represent a broad concept. Nonetheless, there is firm evidence for the validity of the PVQ21. Multidimensional scaling and multi-group confirmatory factor analyses of PVQ21 data support the near equivalence of meaning of the values across ESS countries (Bilsky, Janik, \& Schwartz, 2011; Schwartz \& Rubel, 2005). We controlled for individual differences in scale use by centering individuals' value scores on their own mean response (Schwartz, 1992, 2005). This converted absolute scores into scores that indicate the individual's value priorities.

Control variables. We included age, gender, and education as control variables because they influence value priorities (Schwartz, 1992; Schwartz \& Rubel, 2005). We used number of completed years of education to index education level.

Cultural Egalitarianism. Four PVQ items measured country level Cultural Egalitarianism: equality, tolerance, help and care for others, and loyalty. This index was confirmed by multidimensional analyses of the sample means for the 21 PVQ items across both the 32 countries in this study and across 115 ethno-linguistic subsamples distinguishable in the ESS rounds 1-3 data. Both analyses yielded the same spatial regions for each cultural value in the Schwartz (2006a) theory. These four items, chosen a priori, formed the region that represented Cultural Egalitarianism. We calculated a Cultural Egalitarianism score for each country by aggregating responses to these items across respondents from that country. Coefficient alpha for this index, based on the 32 countries, was .87 .

Human Development Index (HDI). We used the 2004 HDI of the United Nations Development Programme (UNDP; 2005) as an indicator of socio-economic development. This index assesses country development levels based on three indicators: life expectancy, adult literacy and the logarithm of purchasing power adjusted per capita GDP. 


\section{Analyses}

Each individual respondent was nested within one cultural sample. To take the hierarchical structure of the data into account when testing the hypotheses, we conducted multilevel modeling analyses using the Hierarchical Linear Modeling program HLM 6.0 (Raudenbush, Bryk, Cheong, Congdon, \& Du Toit., 2011). We ran separate random-coefficients regression models to predict LS and NA with each of the ten values. As level-1 predictors, we included age, gender, years of education, and one basic value. We group centered these predictors and treated the value as a random variable whose slope could vary across countries. A random intercept was modelled to account for the interdependence of respondents in each country. As level-2 predictors, we included Cultural Egalitarianism and HDI and, to assess the moderation effect of Egalitarianism, the cross-level interaction between the values and Egalitarianism.

\section{Results}

Online supplement B presents descriptive statistics for each country: means for life satisfaction (LS), depressive affect (DEP), the ten values, and scores on Cultural Egalitarianism and HDI. The between-country variance in the dependent variables was $21.2 \%$ for LS and 9.6\% for DEP, making multilevel analyses appropriate. The two country-level variables, HDI and Egalitarianism, correlated highly across samples, as expected $(r=.73, p<.001)$.

Tables 3 and 4 present results of the analyses for LS. The second row of the tables indicates the individual level association of each value with LS. As hypothesized, self-direction, stimulation, and hedonism values related positively to LS (hypothesis 1) and security and tradition values related negatively to LS (hypothesis 2). The association of conformity values to LS was in the hypothesized negative direction but was not significant. As hypothesized, benevolence values related positively to LS (hypothesis 3) and power values related negatively 
to LS (hypothesis 4). As expected, neither universalism nor achievement values related significantly to LS. Rows 3 and 4 of the tables indicate the associations of the two country level predictors with country level LS. Both Cultural Egalitarianism and HDI predicted higher LS.

Next, we examined the cross-level interactions that test moderation by Egalitarianism of relations between values and LS. Visual portrayals of the interactions in Figures 2 and 3, to be explained below, will aid in following these results. Row 5 of Table 3 presents significant negative coefficients for the three openness to change values, indicating that these values relate more positivity to LS in less egalitarian countries, supporting hypothesis 5 . This row also presents significant negative coefficients for power and achievement values, indicating that they relate less negatively to LS in less egalitarian countries, supporting hypotheses $6 a$ and 6 b. Row 5 of Table 4 presents significant positive coefficients for the three conservation values, indicating that they relate more negatively to LS in less egalitarian countries, supporting hypothesis 7 . This row also presents significant positive coefficients for universalism and benevolence values, indicating that they relate less positively to LS in less egalitarian countries, supporting hypotheses $8 \mathrm{a}$ and $8 \mathrm{~b}$.

Row 6 in each table presents the random intercepts for values and row 7, the random slopes for the values. As expected, these were all significant, confirming that it was appropriate to examine moderators that explain the heterogeneity of slopes across countries. In order to save space, we present only the average coefficients for control variables in a footnote to each Table. These show that LS decreases with age and being female and increases with years of education.

Tables 5 and 6 present results of the HLM analyses for DEP. We hypothesized that the effects would be the mirror opposite of those for LS. In line with that assumption, self-direction, hedonism and power values related negatively to DEP and security, tradition, and benevolence 
values related positively to DEP. However, although relations of stimulation and conformity values to DEP were in the hypothesized direction, they were not significant. As expected, universalism and achievement values were unrelated to DEP. Rows 3 and 4 show that HDI but not Egalitarianism predicted lower DEP.

Row 5 of tables 5 and 6 presents the cross-level interactions that test moderation by Egalitarianism of relations between values and DEP. Row 5 of Table 5 presents significant negative coefficients for stimulation and self-direction, indicating that these values relate more negatively to DEP in less egalitarian countries, as expected. The similar moderation anticipated for hedonism was not significant. This row also presents a significant positive interaction for achievement, indicating that these values relate more positively to DEP in less egalitarian countries, as expected. The similar moderation anticipated for power was not significant. Row 5 of Table 6 presents significant negative coefficients for the three conservation values, indicating that they relate more positively to DEP in less egalitarian countries. The non-significant coefficients for benevolence and universalism indicate that Egalitarianism did not moderate relations of these values to DEP, contrary to expectations.

To evaluate the simple slopes of the significant cross-level interactions, we applied the Preacher, Curran and Bauer (2006) tools for a level-1 predictor with a level-2 moderator. Figure 2 portrays the slopes for LS and Figure 3 for DEP. The figures show the patterns of association at three levels of Cultural Egalitarianism, low (mean -1 SD), moderate (mean), and high (mean $+1 \mathrm{SD})$. In sum, the slopes analyses supported all 10 of our hypotheses regarding moderating effects of Egalitarianism on relations of values with LS. The slopes analyses supported six of our 10 hypotheses regarding moderating effects for DEP. The pattern of the slopes corresponded to 
the predicted pattern of moderation by Egalitarianism in the other cases too, but the other four predicted interaction terms were not significant.

\section{Discussion}

This study examined associations of the ten basic individual values in the Schwartz (1992) theory of basic human values with life satisfaction (LS) and depressive affect (DEP) and the moderation of these associations by Cultural Egalitarianism. Results from large national representative samples suggested that the combination of the growth vs. protection and personal vs. social underpinning of each value can explain its overall association with LS across 32 countries and with DEP across 25 countries. Moreover, the cultural context of Egalitarianism in these countries can explain variation in the strength and direction of the value-SWB associations in most cases.

Across countries, openness to change values (self-direction, stimulation, and hedonism), with their growth orientation and personal focus, related positively to SWB. This supported hypothesis 1, although the association of stimulation values with DEP was not significant. In contrast, conservation values (security and tradition), with their protection orientation and social focus related negatively to SWB, supporting hypothesis 2 . Conformity values related to LS and DEP in the expected directions, but its coefficients failed to reach significance. Thus, these findings fit the theorizing about the implications for SWB of the growth vs. protection orientation and personal vs. social focus of basic values.

The growth orientation and social focus that underlie self-transcendence values (benevolence and universalism) have opposing implications for SWB. We hypothesized and found that benevolence values nonetheless related positively to SWB because their social focus pertains to the welfare of family and friends. This focus promotes positive relations that satisfy 
relatedness needs and thereby increase well-being. Universalism values showed no overall association with SWB, as expected and consistent with previous research (Sortheix \& Lönnqvist, 2014). This supports our reasoning that the concern for the problems of others in society that universalism promotes counters its positive growth orientation and reduces SWB.

The self-protection orientation and person focus that underlie self-enhancement values (power and achievement) also have opposing implications for subjective well-being. This led to the expectation, supported by our findings, of no overall association between achievement values and SWB. As expected, power values related negatively to SWB. We predicted this because the person focus of power values motivates pursuit of dominance, an extrinsic goal likely to be detrimental to personal well-being (Deci \& Ryan, 2000) and to elicit negative reactions from others. Hence, this person focus is likely to contribute little to well-being. This finding is consistent with studies showing negative relations of wealth and status goals with SWB (e.g., Kasser et al., 2004).

The theorizing in past research on direct relations of values to SWB explained some of the observed associations (summarized in online supplement A) but offered no comprehensive explanation of the full pattern of findings. By drawing upon the two dynamic underpinnings of values, we were able to predict direct associations of eight basic values with both aspects of SWB and to specify two values for which we expected no association. For both aspects of SWB, all associations were in the predicted direction.

Bobowik et al. (2011) suggested that the congruence between a person's values and those prevalent in the society promotes SWB (Bobowik et al., 2011; cf. Fulmer et al., 2010 for personality traits). Our theorizing argued that value-SWB relations do not depend on cross-level congruence/similarity. Rather, they depend on the particular dynamic motivations that underlie 
each value and their interaction with the surrounding societal context. The congruence hypothesis implies that a value should correlate more positively with SWB the higher its average endorsement in a country. Schwartz (2012) reported a test of this hypothesis for LS in the 32 samples analyzed here. Contradicting the hypothesis, self-direction, stimulation, hedonism, security, conformity and tradition values correlated less positively with LS the greater their average endorsement in a country. In contrast, the combination of the growth vs. protection and personal vs. social underpinnings of these six values correctly predicted their relations to LS.

To develop the moderation hypotheses, we drew on the mechanism of complementary fit. We considered the extent to which pursuing each personal value might help individuals to compensate for what the environments of societies that are low in Cultural Egalitarianism fail to provide. Theory and past research (Schwartz, 2014; Siegel, Licht, \& Schwartz, 2011) characterize the environment in less culturally egalitarian societies as relatively threatening, unstable, anxiety-provoking and constraining. Normative support for cooperation is low and competitive striving more legitimate. Because such societies provide few resources, individuals must draw more upon their own capacities and resources and take personal initiatives in order to succeed. In contrast, more culturally egalitarian societies provide a supportive and predictable environment that encourages cooperative efforts. Such societies enjoy higher levels of affluence and invest in the welfare of their citizens. Hence, it is easier for individuals to obtain what they need whatever their value priorities.

We theorized that person-focused values help individuals to compensate for what is lacking in the environment of societies low in Egalitarianism. Person-focused values motivate individuals to engage actively in pursuing personal interests, to develop and utilize their unique ideas and capacities, to take risks, and to challenge the status quo. Based on this reasoning, we 
hypothesized that person-focused values relate more positively (or less negatively) to SWB under low than under high Cultural Egalitarianism. In line with hypothesis 5, the three openness to change values related more positively to LS under low Egalitarianism. Egalitarianism also moderated the associations of self-direction and stimulation with DEP, but not the association of hedonism. In line with hypotheses $6 \mathrm{a}$ and $6 \mathrm{~b}$, achievement and power values related less negatively to SWB under low Egalitarianism. The finding for power values accords with findings in past research showing that power values related less negatively to LS in low HDI countries (Sortheix \& Lönnqvist, 2014) and that materialistic interests related less negatively to well-being in less developed countries (Dittmar, 2008). However, Cultural Egalitarianism did not moderate relations of power values to DEP.

We further theorized that social-focused values are unlikely to help individuals to compensate for what is lacking in the environment of societies low in Egalitarianism. Socialfocused values motivate the pursuit of harmony rather than the self-assertive energy and skill development needed to cope successfully with difficult institutional and economic circumstances. Moreover, conservation values, with their goal of self-protection, are likely to increase anxiety when the sources of threat are largely due to circumstances beyond individuals' control. Based on this reasoning, we hypothesized that social-focused values relate more negatively (or less positively) to SWB under low than under high Cultural Egalitarianism. In line with this analysis, the three conservation values related more negatively to SWB under low Egalitarianism, supporting hypothesis 7.

The reasoning regarding social-focused values also applies to universalism and benevolence values. Moreover, the problems of others whose welfare these values seek to promote are usually more severe and less amenable to solution in low egalitarian societies. This 
is likely to undermine SWB. We therefore hypothesized that universalism and benevolence values relate less positively (or more negatively) to SWB under low Egalitarianism. Findings supported hypothesis 8 for LS, but despite trends in the expected direction, moderations were not significant for DEP.

Our theorizing that combined an analysis of the life circumstances in societies low vs. high in Cultural Egalitarianism with the implications of pursuing person-focused vs. socialfocused values predicted the pattern of interactions for the ten values and SWB in a more comprehensive way than that presented in Sortheix and Lönnqvist (2014) using HDI. Sortheix and Lönnqvist (2014) found that HDI moderated the associations of 8 values and LS. However, the patterns of moderation for some values were not consistent with their hypotheses. Their theorizing suggesting that all social-focused values would relate positively to LS in highly developed countries was not supported. Furthermore, they did not explain why openness to change values were also positively related to LS in highly developed countries. Egalitarianism correlated substantially with HDI across the 32 countries in our study $(r=.73)$. Like HDI, it points to the level of economic strain in a country and according to our findings it regulates the costs and benefits of pursuing social or personal-focused values in a more consistent way than HDI.

Four of the ten predicted cross-level interactions for DEP were not significant. Thus, cultural moderation of value-SWB relations was weaker for DEP than for LS. A difference between the cognitive and affective components of SWB, discussed in the personality literature, may explain this. Schimmack and colleagues (2002) suggested that culture moderates the influence of personality on the cognitive component of SWB but that the influence of personality on the emotional component of SWB is pancultural. A comparison of the slopes in Figure 2 (LS) 
and Figure 3 (DEP) reveals the relative strength of the associations with the two components of SWB. For every value, the difference in value-SWB associations as a function of Cultural Egalitarianism was greater for the cognitive component, usually substantially so. A comparison of the $t$ values for the slopes in the HLM analyses yields the same conclusion. These findings support the Schimmack et al. (2002) view that culture moderates relations of personality to the cognitive component of SWB. However, the fact that Cultural Egalitarianism moderated relations of six values to DEP contradicts the claim that the influence of personality on the emotional component of SWB is pancultural. Our findings suggest that it is more accurate to conclude that culture has a weaker moderating effect on relations of personality to the affective component of SWB than to the cognitive component.

We included HDI as a country-level variable in our analyses in order to ask whether culture, in the form of Cultural Egalitarianism, had any direct effects on SWB above and beyond those of the socio-economic context. Diener, et al. (2010) reported that HDI, a measure of material living conditions, positively influenced the cognitive aspect of SWB. Our data revealed a similar effect for both the cognitive and affective components of SWB. Cultural Egalitarianism had a weaker positive effect on country-level LS but no direct effect on country- level DEP. Thus, the socio-economic context appears to be more important for the average level of SWB in a country than the aspect of culture we measured.

Although values explain only limited variance in SWB, it is noteworthy that the pattern of significant positive and negative associations fits theorizing based on the dynamic underpinnings of basic values. Value associations with SWB are comparable to those of other psychological variables. Meta-analyses of predictors of LS (Richard, Bond, \& Stokes-Zoota, 2003), including social activity, ethnicity, marital status, and gender, reported effect sizes 
ranging from $r=.00$ (gender) to $r=.15$ (social activity). We calculated equivalent effect sizes for values as predictors of LS in the ESS data. These ranged from $r=.03$ (universalism) to $r=$ .19 (security).

\section{Limitations}

Two limitations of this study should be noted. First, the analyses relied on cross-sectional data and could not shed light on causality between values and SWB. Some degree of reciprocal causality is likely. Longitudinal and experimental studies are needed to clarify the dynamics of value-SWB associations. Second, we measured both values and SWB with self-reports. Although the questions tapping SWB preceded those tapping values in the interview by approximately half an hour, there may have been some influence of the former on the latter. Non-self-report methods to measure both types of variables are being developed, but they are not suitable for large-scale surveys across countries. Fortunately, many studies have shown that the self-report measures used here demonstrate substantial validity in their theory-based relations to other variables.

\section{Conclusion}

The current study goes beyond prior research on relations between values and SWB in several ways. (1) It investigates a larger and more heterogeneous set of countries than any previous study. (2) It considers relations of values to both LS, a cognitive, positive aspect of SWB and DEP, an emotional, negative aspect. (3) It derives hypotheses from theorizing about both dynamic bases of values, growth vs protection orientation and person- vs. social-focus. (4) It demonstrates moderation of value-SWB associations by the cultural context of Egalitarianism. (5) It identifies complementary fit as a theoretical mechanism useful for explaining the moderation effects of the cultural context on the value-SWB relations. (6) By including 
representative samples from 32 countries from East and West Europe and the Middle East, it responds to calls for including more heterogeneous samples of countries in research (Sortheix \& Lönnqvist, 2014; Fischer \& Boer, 2011).

Our reasoning and findings regarding the mechanisms that underlie the cross-level interactions between Cultural Egalitarianism and values in predicting SWB contribute to the socio-ecological approach to psychological processes (Oishi, 2014). This approach focuses on the physical, societal, and interpersonal environments that influence the human mind and behavior. This study has demonstrated how the cultural context can shape the links between individual psychological variables. Associations of values with SWB varied significantly across a heterogeneous set of 32 countries. Country levels of Cultural Egalitarianism explained much of this variability. Cultural Egalitarianism holds promise as a potential moderator of other individual psychological processes as well. 


\section{References}

Bardi, A., Guerra, V. M., \& Ramdeny, G. S. D. (2009). Openness and ambiguity intolerance: Their differential relations to well-being in the context of an academic life transition. Personality and Individual Differences, 47(3), 219-223.

Bilbao, M. A., Techio, E. M., \& Paez, D. (2007). Felicidad, cultura y valores personales: estado de la cuestión y síntesis meta-analítica. [Happiness, culture and personal values: current situation and meta-analytic synthesis]. Revista de Psicología-Lima, 25, 223-276.

Bilsky, W., Janik, M., \& Schwartz, S. H. (2011). The structural organization of human values Evidence from three rounds of the European Social Survey (ESS). Journal of Cross-Cultural Psychology, 42, 759-776.

Bilsky, W., \& Schwartz, S.H. (1994). Values and personality. European Journal of Personality, $8,163-181$

Bobowik, M., Basabe, N., Páez, D., Jiménez, A., \& Bilbao, M. Á. (2011). Personal values and well-being among Europeans, Spanish natives and immigrants to Spain: Does the culture matter? Journal of Happiness Studies, 12(3), 401-419.

Bradburn, N. M. (1969). The structure of psychological well-being. Oxford, England: Aldine.

Cable, D. M., \& Edwards, J. R. (2004). Complementary and supplementary fit: a theoretical and empirical integration. Journal of applied psychology, 89(5), 822.

Cacioppo, J. T., \& Berntson, G. G. (1999). The affect system architecture and operating characteristics. Current Directions in Psychological Science, 8(5), 133-137.

Cohen, A., \& Shamai, O. (2009). The relationship between individual values, psychological well-being, and organizational commitment among Israeli police officers. International Journal of Police Strategies \& Management, 33, 30-51. 
Deci, E. L., \& Ryan, R. M. (2000). The "what" and "why" of goal pursuits: Human needs and the self-determination of behavior. Psychological Inquiry, 11, 227-268.

Diener, L. Lucas, R., Schimmack, U., \& Helliwell, J. (2009). Wellbeing for public policy (Eds.). Oxford University Press.

Diener, E., Ng, W., Harter, J., \& Arora, R. (2010). Wealth and happiness across the world: Material prosperity predicts life evaluation, whereas psychosocial prosperity predicts positive feeling. Journal of Personality and Social Psychology, 99, 52-61.

Diener, E., Oishi, S., \& Lucas, E. (2003). Personality, culture and Subjective well-being: emotional and cognitive evaluations of life. Annual Review of Psychology, 54, 403-25.

Dittmar, H. (2008). Consumer culture, identity and well-being: The search for the 'good life' and the 'body perfect'. New York: Psychology Press.

Fischer, R., \& Boer, D. (2011). What is more important for national well-being: Money or autonomy? A meta-analysis of well-being, burnout, and anxiety across 63 societies. Journal of Personality and Social Psychology, 101, 164-184.

Fulmer, C. A., Gelfand, M. J., Kruglanski, A. W., Kim-Prieto, C., Diener, E., Pierro, A., \& Higgins, E. T. (2010). On "feeling right" in cultural contexts how person-culture match affects self-esteem and subjective well-being. Psychological Science, 28, 1563-1569.

Grucza, R. A., Przybeck, T. R., Spitznagel, E. L., \& Cloninger, C. R. (2003). Personality and depressive symptoms: a multi-dimensional analysis. Journal of Affective Disorders, 74, 123130.

Helliwell, J., Layard, R., \& Sachs, J. (Eds.) (2012). World happiness report. The Earth Institute, Columbia University, New York, USA. 
Howell, R. T., Kern, M. L., \& Lyubomirsky, S. (2007). Health benefits: Meta-analytically determining the impact of well-being on objective health outcomes. Health Psychology Review, 1, 83-136.

Joshanloo, M., \& Ghaedi, G. (2009). Value priorities as predictors of hedonic and eudaimonic aspects of well-being. Personality and Individual Differences, 47, 294-298.

NSD (2002-2007). European Social Survey data. Bergen: Norwegian Social Science Data Service. [NSD: http://ess.nsd.uib.no].

Kasser, T., Ryan, R. M., Couchman, C. E., \& Sheldon, K. M. (2004). Materialistic values: Their causes and consequences. In T. Kasser \& A. D. Kanner (Eds.), Psychology and consumer culture: The struggle for a good life in a materialistic world (pp. 11-28). Washington, DC, US: American Psychological Association.

Kristof, A. L. (1996). Person-organization fit: An integrative review of its conceptualizations, measurement, and implications. Personnel psychology, 49(1), 1-49.

Kööts-Ausmees, L., \& Realo, A. (2015). The association between life satisfaction and selfreported health status in Europe. European Journal of Personality, 29, 647-657.

Lucas, R. E., Diener, E., \& Suh, E. (1996). Discriminant validity of well-being measures. Journal of Personality and Social Psychology, 71(3), 616.

Lyubomirsky, S., King, L., \& Diener, E. (2005). The benefits of frequent positive affect: does happiness lead to success? Psychological Bulletin, 131 (6), 803-855.

Lönnqvist, J. E., Jasinskaja-Lahti, I., \& Verkasalo, M. (2011). Personal values before and after migration: A longitudinal case study on value change in Ingrian-Finnish migrants. Social Psychological and Personality Science, 1948550611402362.

Maslow, A. H. (1954). Motivation and Personality. New York: Harper. 
Muchinsky, P. M., \& Monahan, C. J. (1987). What is person-environment congruence? Supplementary versus complementary models of fit. Journal of vocational behavior, 31(3), 268-277.

Oishi, S. (2014). Socioecological psychology. Annual Review of Psychology, 65, 581-609.

Oishi, S., Diener, E. F., Lucas, R. E., \& Suh, E. M. (1999). Cross-cultural variations in predictors of life satisfaction: Perspectives from needs and values. Personality and Social Psychology Bulletin, 25, 980-990.

O'Reilly, C. A., Chatman, J., \& Caldwell, D. F. (1991). People and organizational culture: A profile comparison approach to assessing person-organization fit. Academy of management journal, 34(3), 487-516.

Richard, F. D., Bond, C. F., Jr., \& Stokes-Zoota, J. J. (2003). One hundred years of social psychology quantitatively described. Review of General Psychology, 7, 331-363.

Rokeach, M. (1973). The nature of human values (Vol. 438). New York: Free press.

Russell, J. A., \& Carroll, J. M. (1999). On the bipolarity of positive and negative affect. Psychological Bulletin, 125, 3-30.

Sagiv, L., \& Schwartz, S. H. (2000). Value priorities and subjective well-being: Direct relations and congruity effects. European Journal of Social Psychology, 30, 177-198.

Sagiv, L., Roccas, S., \& Oppenheim, S. (2015). Values and well-being. In: S. Joseph (Ed.). Positive Psychology in Practice. 2nd Edition (pp. 103-121). NY: John Wiley.

Schimmack, U., Radhakrishnan, P., Oishi, S., Dzokoto, V. \& Ahadi, S. (2002). Culture, personality, and subjective well-being: Integrating process models of life-satisfaction. Journal of Personality and Social Psychology, 82, 582-593 
Schwartz, S. H. (1992). Universals in the content and structure of values: Theory and empirical tests in 20 countries. In M. Zanna (Ed.), Advances in experimental social psychology (Vol. 25) (pp. 1-65). New York: Academic Press.

Schwartz, S. H. (2005). Human values. European Social Survey Edunet. Website: http://essedunet.nsd.uib.no/cms/topics/1/

Schwartz, S. H. (2006a). A theory of cultural value orientations: Explication and applications. Comparative Sociology, 5, 137-182.

Schwartz, S. H. (2006b). Les valeurs de base de la personne: Théorie, mesures et applications [Basic human values: Theory, measurement, and applications]. Revue Française de Sociologie, 47, 249-288.

Schwartz, S. H. (2012, November). Do personal values underlie or undermine happiness? Cultural effects. Paper presented at the European Social Survey International Conference, Nicosia, Cyprus.

Schwartz, S. H. (2014). National culture as value orientations: Consequences of value differences and cultural distance. In V. Ginsburgh \& D. Throsby (Eds.), Handbook of the Economics of Art and Culture, Vol.2 (pp. 547-586). Elsevier/North Holland.

Schwartz, S. H. (2015). Basic individual values: Sources and consequences. In D. Sander and T. Brosch (Eds.), Handbook of value. Oxford: UK, Oxford University Press.

Schwartz, S. H., \& Rubel, T. (2005). Sex differences in value priorities: Cross-cultural and multi-method studies. Journal of Personality and Social Psychology, 89, 1010-1028.

Siegel, J. I., Licht, A. N., \& Schwartz, S. H. (2011). Egalitarianism and international investment. Journal of Financial Economics, 102(3), 621-642. 
Sortheix, F. M., \& Lönnqvist, J. E. (2014). Personal value priorities and life satisfaction in Europe: The moderating role of socioeconomic development. Journal of Cross-Cultural Psychology, 45(2), 282-299.

United Nations Development Programme (UNDP; 2005). Human Development Report 2005. International cooperation at crossroads. Retrieved from: http://hdr.undp.org/sites/default/files/reports/266/hdr05_complete.pdf

Van de Velde, S., Bracke, P., Levecque, K., \& Meuleman, B. (2010). Gender differences in depression in 25 European countries after eliminating measurement bias in the CES-D 8. Social Science Research, 39(3), 396-404.

Verkasalo, M., Goodwin, R., \& Bezmenova, I. (2006). Values following a major terrorist incident: Finnish adolescent and student values before and after September 11, 2001. Journal of Applied Social Psychology, 36(1), 144-160. 
Table 1. List of the ten basic values and their definition in terms of motivational goals

\begin{tabular}{|c|c|}
\hline Value & Motivational goals \\
\hline Security & Safety, harmony and stability of society, of relationships, and of self \\
\hline Conformity & $\begin{array}{l}\text { Restraint of actions likely to upset others and violate social expectations or } \\
\text { norms }\end{array}$ \\
\hline Tradition & $\begin{array}{l}\text { Respect, commitment and acceptance of the customs and ideas that traditional } \\
\text { culture or religion provide the self }\end{array}$ \\
\hline Benevolence & $\begin{array}{l}\text { Preservation and enhancement of the welfare of people with whom one is in } \\
\text { frequent personal contact }\end{array}$ \\
\hline Universalism & Understanding, and protection for the welfare of all and the environment \\
\hline Self-Direction & Independent thought and action-choosing, creating, exploring \\
\hline Stimulation & Excitement, novelty and challenge in life \\
\hline Hedonism & Pleasure and sensuous gratification for oneself \\
\hline Achievement & $\begin{array}{l}\text { Personal success through demonstrating competence according to social } \\
\text { standards }\end{array}$ \\
\hline Power & Social status and prestige, control or dominance over people and resources \\
\hline
\end{tabular}


Table 2. Theorized associations between values and subjective well-being based on crossing two sets of motivations underlying values: growth versus self-protection and person versus social focus.

\begin{tabular}{|l|c|c|}
\hline Motivational Bases of Values & Growth-Positive (+) & Self-Protection-Negative (-) \\
\hline and their Effects on SWB & Hedonism, Stimulation, & Power \\
Person Focus-Positive (+) & Self-Direction & Achievement \\
& $(++)$ & $(+-)$ \\
\hline Social Focus-Negative (-) & Benevolence & Security, Tradition \\
& Universalism & Conformity \\
& $(+-)$ & $(-)$ \\
\hline
\end{tabular}

Note: $(++)=$ positive associations; $(--)=$ negative associations; $(+-)$ and $(-+)=$ complex associations 
Table 3. Predicting life satisfaction with individual values (person-focused), controls, and the interaction between individual values and Egalitarianism

\begin{tabular}{|c|c|c|c|c|c|c|c|c|c|c|}
\hline & \multicolumn{2}{|c|}{ Self-Direction } & \multicolumn{2}{|c|}{ Stimulation } & \multicolumn{2}{|c|}{ Hedonism } & \multicolumn{2}{|c|}{ Achievement } & \multicolumn{2}{|c|}{ Power } \\
\hline \multicolumn{11}{|l|}{ Individual-level $^{\mathrm{A}}$} \\
\hline Value & $.10 * * *$ & -.02 & $.05^{*}$ & .02 & $.15 * * *$ & .02 & -.02 & .02 & $-.13 * * *$ & .02 \\
\hline Egalitarianism & $1.85^{*}$ & $2.66^{* *}$ & $2.19 * *$ & .81 & $1.65^{*}$ & .81 & $2.66 * *$ & .79 & $1.87^{*}$ & .82 \\
\hline HDI & $8.35 * * *$ & $5.05 *$ & $6.99 * *$ & 2.19 & $9.20 * *$ & 2.50 & $5.05 *$ & 1.96 & $8.29 * *$ & 2.93 \\
\hline Interaction: Value $x$ Egalitarianism & $-.70 * * *$ & $-.68 * * *$ & $-.61 * * *$ & .10 & $-.35 * * *$ & .09 & $-.68 * * *$ & .12 & $-.22 *$ & .08 \\
\hline Variance components & Variance & $\chi^{2}$ & Variance & $\chi^{2}$ & Variance & $x^{2}$ & Variance & $\chi^{2}$ & Variance & $\chi^{2}$ \\
\hline Residual variance & \multicolumn{2}{|c|}{3.19} & \multicolumn{2}{|c|}{3.19} & \multicolumn{2}{|c|}{3.18} & \multicolumn{2}{|c|}{3.19} & \multicolumn{2}{|c|}{3.19} \\
\hline
\end{tabular}

${ }^{*} p<.05, * * p<.01, * * * p<.001$ Note. Coeff. $=$ HLM coefficient. $N=121,495$

${ }^{\mathrm{A}}$ Average effects for control variables: age (Coeff. $\left.=-.007^{* *}, S E=.002\right)$, gender (male $=0$, female $=1$, Coeff. $\left.=.009, S E=.006\right)$, years of education (Coeff. $\left.=.037^{* * *}, S E=.005\right)$. 
Table 4. Predicting life satisfaction with individual values (social-focused), controls, and the interaction between individual values and Egalitarianism

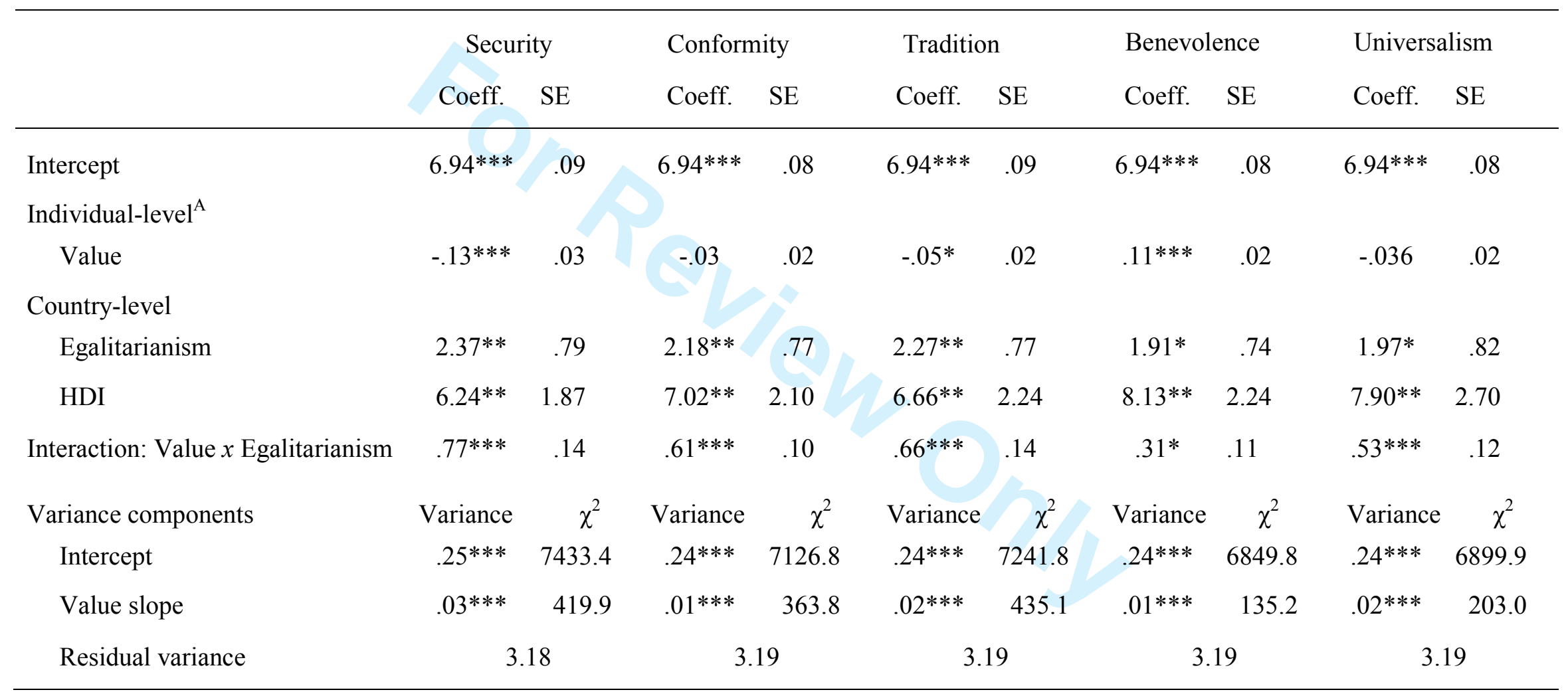

$* p<.05, * * p<.01, * * * p<.001$. Note. Coeff. $=$ HLM coefficient. $N=121,495$.

${ }^{\mathrm{A}}$ Average effects for control variables: age (Coeff. $\left.=-.008^{* * *}, S E=.002\right)$, gender (Coeff. $\left.=.008, S E=.006\right)$, years of education (Coeff. $\left.=.038^{* * *}, S E=.005\right)$. 
Table 5. Predicting depressive affect with individual values (person-focused), controls, and the interaction between individual values and Egalitarianism

\begin{tabular}{|c|c|c|c|c|c|c|c|c|c|c|}
\hline & \multicolumn{2}{|c|}{ Self-Direction } & \multicolumn{2}{|c|}{ Stimulation } & \multicolumn{2}{|c|}{ Hedonism } & \multicolumn{2}{|c|}{ Achievement } & \multicolumn{2}{|c|}{ Power } \\
\hline & Coeff. & SE & Coeff. & SE & Coeff. & SE & Coeff. & SE & Coeff. & SE \\
\hline Intercept & $1.63 * * *$ & .02 & $1.63 * * *$ & .02 & $1.63 * * *$ & .02 & $1.63 * * *$ & .02 & $1.63 * * *$ & .02 \\
\hline \multicolumn{11}{|l|}{ Individual-level $^{\mathrm{A}}$} \\
\hline Value & $-.04 * * *$ & .01 & -.01 & .01 & $-.03 * *$ & .01 & .01 & .01 & $.03 * * *$ & .004 \\
\hline \multicolumn{11}{|l|}{ Country-level } \\
\hline Egalitarianism & -.20 & .12 & -.19 & .12 & -.19 & .13 & -.20 & .12 & -.19 & .12 \\
\hline HDI & $-1.93 * * *$ & .31 & $-1.95^{* *}$ & .29 & $-1.95 * * *$ & .39 & $-1.96 * * *$ & .29 & $-1.96 * * *$ & .29 \\
\hline Interaction: Value $x$ Egalitarianism & $.15^{* *}$ & .04 & $.10 * * *$ & .02 & .04 & .03 & $.16^{* * *}$ & .04 & .005 & .03 \\
\hline Variance components & Variance & $\chi^{2}$ & Variance & $\chi^{2}$ & Variance & $\chi^{2}$ & Variance & $\chi^{2}$ & Variance & $\chi^{2}$ \\
\hline Intercept & $.009 * * *$ & 1312.6 & $.009 * * *$ & 1308.4 & $.009 * * *$ & 1432.0 & $.009 * * *$ & 1314.2 & $.009 * * *$ & 1314.06 \\
\hline Value slope & $.001 * * *$ & 72.9 & $.001 * * *$ & 104.4 & $.001 * * *$ & 171.5 & $.001 * * *$ & 168.0 & $.000 * * *$ & 78.9 \\
\hline Residual variance & \multicolumn{2}{|c|}{.247} & \multicolumn{2}{|c|}{.247} & \multicolumn{2}{|c|}{.246} & \multicolumn{2}{|c|}{.247} & \multicolumn{2}{|c|}{.241} \\
\hline
\end{tabular}

$* p<.05, * * p<.01, * * * p<.001$. Note. Coeff. $=$ HLM coefficient. $N=42,972$.

${ }^{\mathrm{A}}$ Average effects for control variables: age $($ Coeff. $=.002 *, S E=.001)$, gender $($ Coeff. $=.062 * * *, S E=.005)$, years of education (Coeff. $\left.=-.016^{* * *}, S E=.002\right)$. 
Table 6. Predicting depressive affect with individual values (social-focused), controls, and the interaction between individual values and Egalitarianism

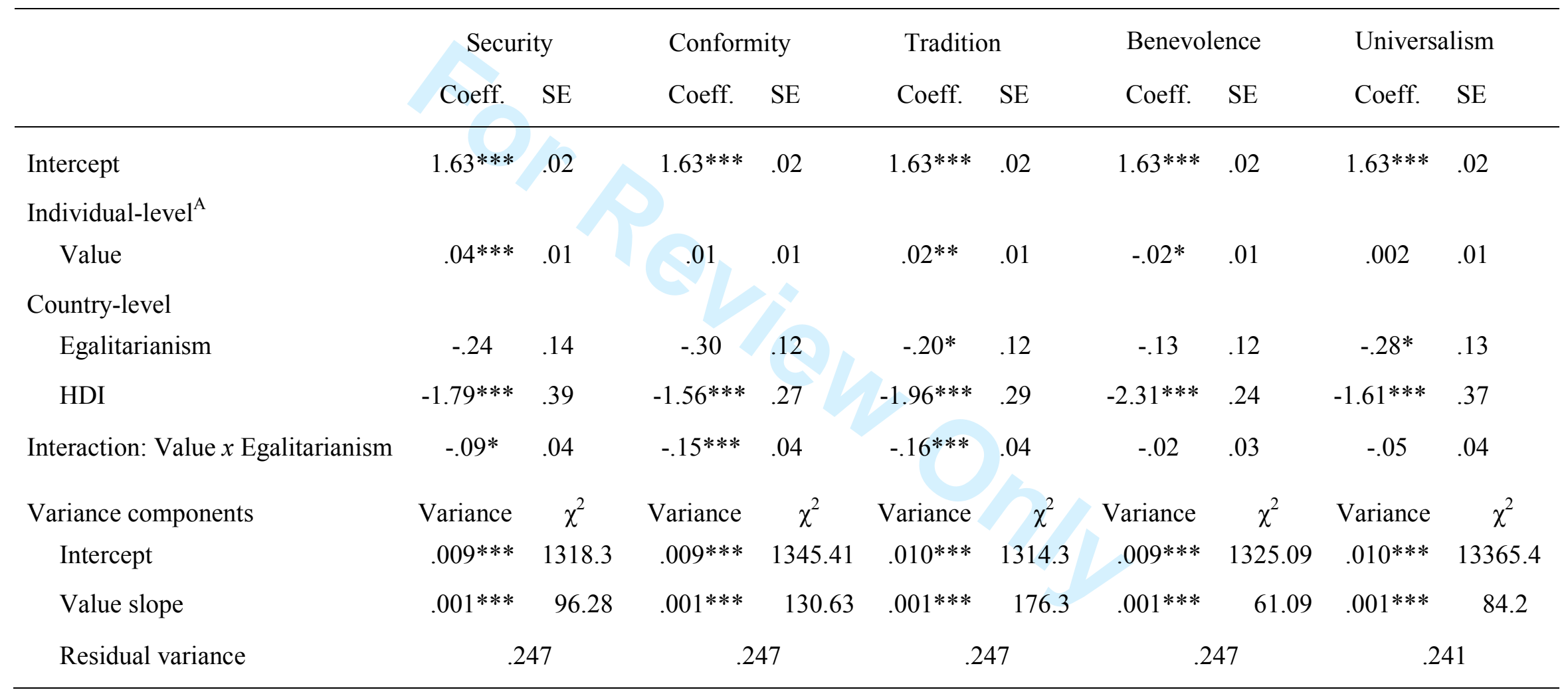

$* p<.05, * * p<.01, * * * p<.001$. Note. Coeff. $=$ HLM coefficient. $N=42,972$.

${ }^{\mathrm{A}}$ Average effects for control variables: age (Coeff. $\left.=.002 *, S E=.001\right)$, gender (Coeff. $\left.=.062 * * *, S E=.005\right)$, years of education (Coeff. $\left.=-.016^{* * *}, S E=.002\right)$. 


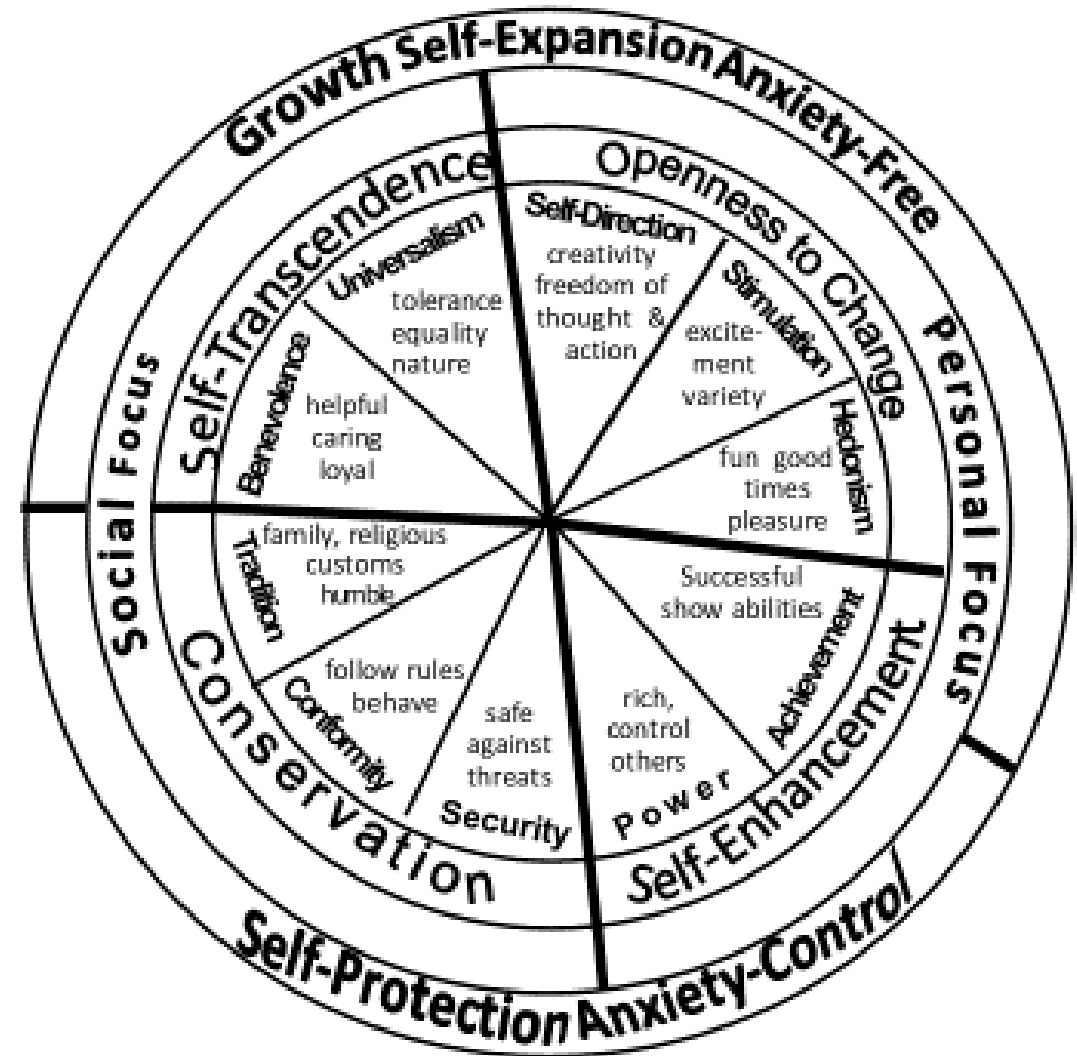

Figure 1. The circular structure of ten basic values, four higher order values, and two underlying motivational sources (adapted from Schwartz, 2015) 


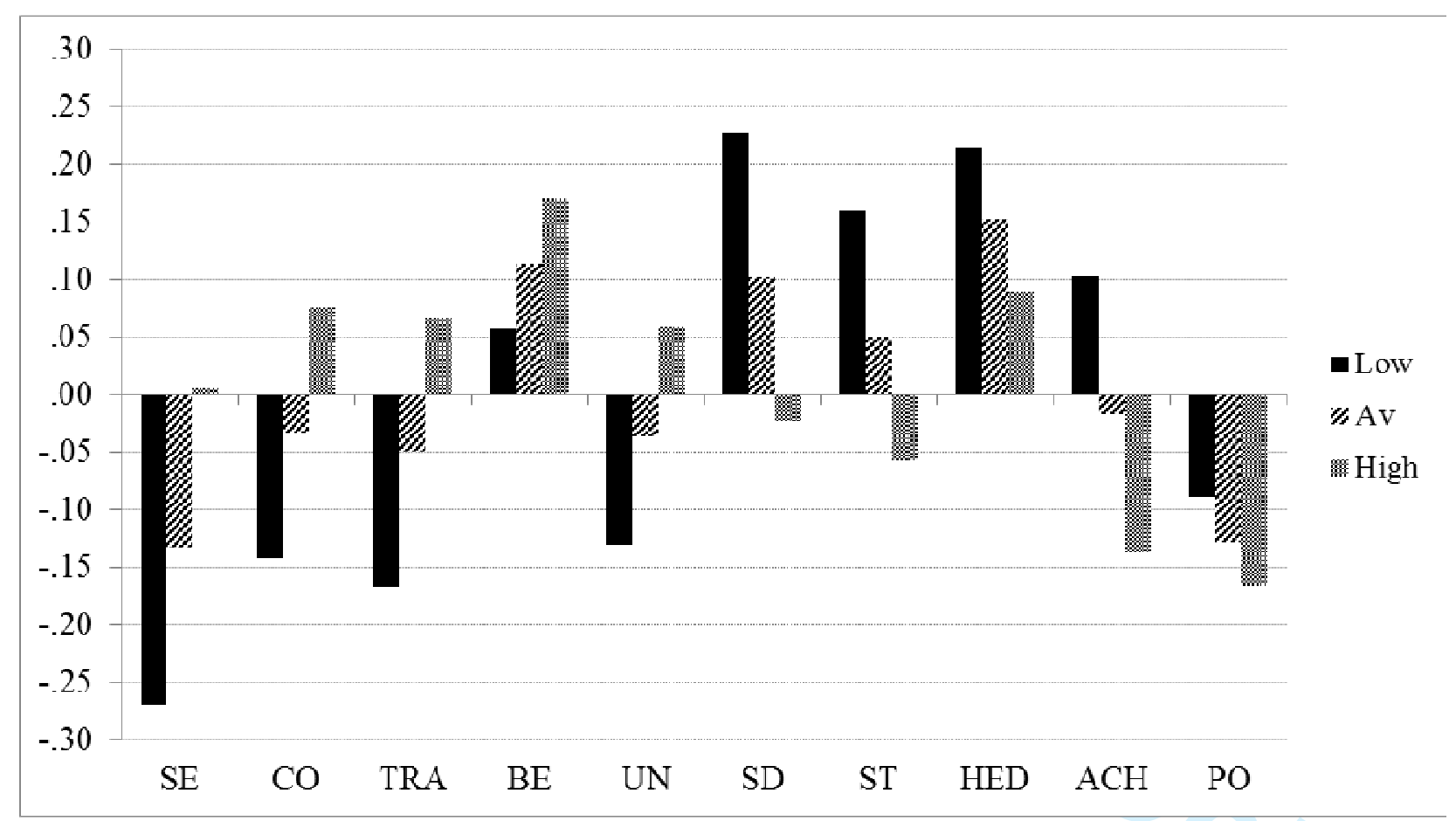

Figure 2. Multilevel slope estimates of the 10 values predicting life satisfaction at high (+1 SD), average (av) and low (-1 SD) levels of egalitarianism.

Note. Slopes larger than $/ .07 /$ are significant at $p<.001$ and slopes larger than /.05/ are significant $p<.01$. 


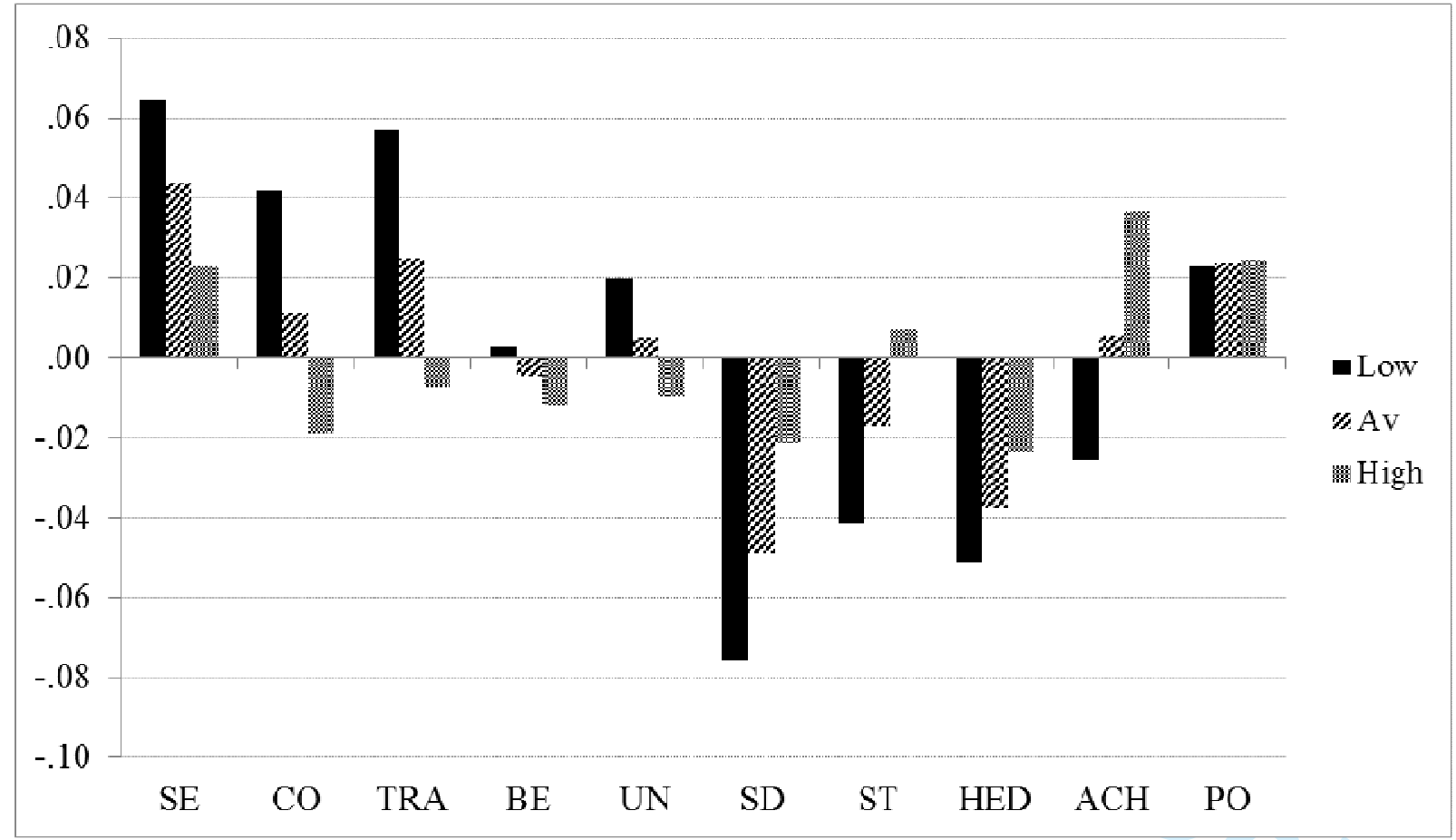

Figure 3. Multilevel slope estimates of the 10 values predicting depressive affect at high (+ $1 \mathrm{SD})$, average (Av) and low (-1 SD) levels of egalitarianism.

Note. Slopes larger than $/ .02 /$ are significant $p<.001$, except achievement at low egalitarianism $(p=.06)$ and hedonism at high egalitarianism $(p .<.05)$. 